autoimmune disorder (s) or autoantibodies were present in $29 \%$ of the relatives. Two of $33(6 \%)$ nonconsangineous relatives had autoimmune disorders and 6/33 (18\%) had autoantibodies.

Conclusion Autoimmune disorders in general are present in increased frequency in these Icelandic multicase SLE families.

\section{THU0251 FAMILIAL CLUSTERING OF AUTOIMMUNE DISEASES IN SJÖGREN'S SYNDROME: AN ITALIAN CASE-CONTROL STUDY}

${ }^{1} \mathrm{R}$ Priori, ${ }^{1} \mathrm{~F}$ Conti, ${ }^{1} \mathrm{E}$ Cassarà, ${ }^{2} \mathrm{E}$ Medda, ${ }^{2} \mathrm{MA}$ Stazi, ${ }^{3} \mathrm{C}$ Tomassini, ${ }^{4} \mathrm{E}$ Bozzolo, ${ }^{5} \mathrm{~F}$ Franceschini, ${ }^{6} \mathrm{~T}$ Urbano, ${ }^{7} \mathrm{R}$ Giacomelli, ${ }^{1} \mathrm{G}$ Valesini. ${ }^{1}$ Rheumatology, "La Sapienza" University; ${ }^{2}$ stituto Superiore Di Sanità, ISS, Rome; ${ }^{3}$ Rheumatic Diseases, University, Perugia; ${ }^{4}$ URIC, H-S. Raffaele, Milano; ${ }^{5}$ Clinical Immunology, University, Brescia; ${ }^{6}$ Internal Medicine, University, Ancona; 'Internal Medicine, University, L'Aquila, Italy

\subsection{6/annrheumdis-2001.795}

Background Autoimmune diseases often cluster in families.

Objectives Aim of this study was to investigate the prevalence, the incidence and the risk for autoimmune diseases (AD) in first degree relatives (FDR) of italian Sjögren's syndrome (SS) patients.

Methods A multicentre case-control study was performed in Italy. Cases (patients classified as SS according to 1994 EEC criteria) and controls (subjects without known history of autoimmune disorder) were randomly selected and interviewed by a trained medical doctor. Data on family history of AD in FDR were recorded. We calculated the incidence rate of $\mathrm{AD}$ in the two groups by dividing the number of cases of $\mathrm{AD}$ by personyears (py) at risk. The relative risk (RR) was estimated by dividing the incidence rate among relatives of cases by the incidence rate among relatives of controls. Furthermore we conducted stratified analyses according to sex of relatives and/or proband to evaluate whether the relation between SS in FDR and AD differs by sex. Statistical analyses were performed using STATA software.

Results 143 SS cases and 140 controls were enrolled. 34/143 $(23.8 \%)$ and $8 / 140(5.7 \%)$ had at least one FDR with AD (p < $0.01) ; 44 / 839$ (5.24\%) FDR of SS patients and 12/776 (1.55\%) FDR of controls had AD $(\mathrm{p}<0.01)$. We estimated an incidence rate of $1.03 \times 1000$ py in SS group and $0.32 \times 1000$ py in control group. The ratio of incidence density showed that relatives of SS cases have three time probability to have an AD compared to relatives of controls (RR 3.24, CI 95\% 1.71-6.14). We found that the risk for $\mathrm{AD}$ is epecially pronounced in relatives of female probands and it increases if the FDR is female, too.

Conclusion This case-control study confirms the clustering of $\mathrm{AD}$ in SS families and defines the risk to have an $\mathrm{AD}$ for first degree relatives of patients with SS.

\section{THU0252 THE PREVALENCE OF SYMPTOMATIC KNEE AND DISTAL INTERPHALANGEAL JOINT OSTEOARTHRITIS IN ELDERLY URBAN POPULATION OF ANTALYA, TURKEY. A PRELIMINARY REPORT}

${ }^{1} \mathrm{C}$ Kaçar, ${ }^{1} \mathrm{~B}$ Bütün, ${ }^{1} \mathrm{C}$ Yildirim, ${ }^{1} \mathrm{E}$ Gilgil, ${ }^{1} \mathrm{G}$ Sümbüloglu, ${ }^{1} \mathrm{I}$ Tekeoglu, ${ }^{1} \mathrm{~V}$ Arikan, ${ }^{1} \mathrm{~S}$ Urhan, ${ }^{1} \mathrm{U}$ Dündar, ${ }^{1} \mathrm{MC}$ Öksüz, ${ }^{2} \mathrm{~A}$ Apaydin, ${ }^{1} \mathrm{~T}$ Tuncer. ${ }^{1}$ Department of Physical Medicine and Rehabilitation; ${ }^{2}$ Department of Radiology, Akdeniz University Faculty of Medicine, Antalya, Turkey

10.1136/annrheumdis-2001.796

Background
Objectives To estimate the prevalence of symptomatic knee and distal interphalangeal joint (DIP) osteoarthritis (OA) in the urban population of Antalya.

Methods This cross-sectional study, as part of a continuing larger study, aimed to evaluate the prevalence of symptomatic knee and DIP OA in the elderly urban population of Antalya (508.840 population according to 1997 national census). By random cluster sampling based on the registries of local offices of the Ministry of Health, 267 individuals aged 50 or over (146 men, 121 women) were interviewed face to face by 10 physicians and 20 medical students trained for the study. The individuals were subjected to a questionnaire regarding knee pain, worsening pain on exertion and gelling phenomenon. They were also asked about their occupational status and performing namaz (an Islamic ritual based on bodily movements). If they reported any swelling in their hand joints, a physician simultaneously inspected the DIP joints for nodular swelling. In the case of suspicion for knee OA, individuals were invited to the hospital for further evaluation by physical examination and direct roentgenogram.

Results Knee pain was reported in $38(28,4 \%)$ of men and 74 $(63,8 \%)$ of women. Of women, $64(57,1 \%)$ had worsened knee pain on exertion and $59(51,3 \%)$ defined gelling, and in men these figures were $26(20,5 \%)$ and $28(21,5 \%)$, respectively. The prevalence of knee osteoarthritis was determined as $26,4 \%$ in women and $6,2 \%$ in men $(15,4 \%$ of total). The DIP OA was observed in $5(3,8 \%)$ of men and $30(26,3 \%)$ of women.

Conclusion OA is a major health problem in the elderly population, especially in more than one fourth of the women aged 50 or over.

This study is supported by the Akdeniz University Research Fund.

\section{THU0253 THE PREVALENCE OF INFLAMMATORY RHEUMATIC DISEASES IN THE URBAN POPULATION OF ANTALYA, TURKEY (A PRELIMINARY STUDY REPORT)}

'B Bütün, 'T Tuncer, ${ }^{1} \mathrm{C}$ Kaçar, ${ }^{1} \mathrm{E}$ Gilgil, ${ }^{1} \mathrm{I}$ Tekeoglu, ${ }^{1} \mathrm{C}$ Yildirim, ${ }^{1} \mathrm{G}$ Sümbüloglu, ${ }^{1} \mathrm{~S}$ Urhan, ${ }^{1} V$ Arikan, ${ }^{1 \ddot{U}}$ Dündar, ${ }^{1} \mathrm{MC}$ Öksüz, ${ }^{2} \mathrm{G}$ Yücel. ${ }^{1}$ Department of Physical Medicine and Rehabilitation and Rheumatology Service; ${ }^{2}$ Department of Biochemistry, Akdeniz University Faculty of Medicine, Antalya, Turkey

10.1136/annrheumdis-2001.797

\section{Background}

Objectives To estimate the prevalence of rheumatoid arthritis, sero-negative spondylarthritis, SLE and other connective tissue diseases in the urban population of Antalya.

Methods The region in which the study was performed is the urban area of Antalya with a population of 508.840(according to 1997 national census) and a high migratory rate. 3000 subjects, 16 years old and more were selected by random cluster sampling. Trained 10 clinicians and 20 medical students visited 1521 subject in their homes (door to door system) so far and detailed interview on the basis of a standardised questionnaire was performed. The patients suspected of inflammatory rheumatic diseases were invited to the hospital and detailed physical examination and laboratory evaluation was done, if necessary. The diagnosis was established by using standard criteria of each diseases.

Results Of subjects, 767 female and 754 male (totally 1521) were evaluated so far. Seven Rheumatoid Arthritis (6 Female, 1 Male), 2 Ankylosing spondylitis (2M), 2 SLE (1M, 1F), 1 Systemic sclerosis (F), 1 Behçet disease (F), 1 Sarcoidosis (F), 1 $\operatorname{FMF}(\mathrm{M})$ were established and thus the point prevalences of 